MONIZ BANDEIRA, Luiz Alberto. 2001. O governo João Goulart : as lutas sociais no Brasil (1961-1964). Rio de Janeiro : Revan; Brasília : EdUnb.

\title{
CONSPIRAÇÃO, POPULISMO E GOLPE DE ESTADO NO BRASIL
}

\author{
Marcus Roberto de Oliveira \\ Universidade Federal do Paraná
}

\begin{abstract}
O golpe de Estado de 31 de março de 1964 foi "um episódio da luta de classes", no qual o "empresariado, sobretudo seu setor estrangeiro, tratou de conter e reprimir a ascensão dos trabalhadores" (MONIZ BANDEIRA, 2001, p. 21-22). Essa definição aparece como a tese principal do livro O governo João Goulart: as lutas sociais no Brasil (1961-1964), de Luiz Alberto Moniz Bandeira, obra que, atualmente em reedição ampliada, já pode ser considerada um clássico sobre a derrocada do sistema populista brasileiro.
\end{abstract}

A partir dessa idéia central, o leitor poderá identificar dois temas que desenvolvem a tese principal. $O$ primeiro deles diz respeito à participação dos EUA na conspiração, atestada após um denso levantamento de dados que esclarecem as atividades da CIA, do Departamento de Estado americano, da embaixada e das multinacionais norte-americanas no processo que visava à queda do governo Goulart. O segundo tema focaliza o papel político do presidente João Goulart, especificamente sua orientação nacional-reformista, posição então expressa em seu programa de "Reformas de Base"1.

A análise da participação dos EUA no movimento conspirador que determinou a queda do populismo no Brasil através de um golpe de Estado, e sobre as posturas de João Goulart no referido período de crise (19611964), são utilizadas constantemente pelo autor para fundamentar sua tese principal, como fica claro na seguinte passagem: "Com efeito, o golpe de Estado no Brasil, instigado e sustentado pela comunidade dos homens de negócios e pelos proprietários de terras, constituiu nitidamente um episódio da luta de classes, a refletir o aguçamento, tanto no nível nacional quanto internacional, dos antagonismos sociais e políticos, que atingiram uma gravidade inaudita na América Latina, a partir do triunfo da Revolução Cubana" (idem, p. 204-205).

A menção aos fatos políticos internos que estiveram presentes no período de crise do populismo (especificamente: os antagonismos de classe), aparecem nessa citação como consequiência de outro fato político posto num primeiro plano e relacionado ao clima da Guerra Fria, ou seja, o recém-constituído regime socialista cubano. Tal argumentação fica evidente ao longo da obra quando Moniz Bandeira explora as questões que dizem respeito às atividades norte-americanas no movimento golpista e às relacionadas ao nacionalreformismo proposto por Goulart.

Sobre a participação dos EUA, o autor lança mão de uma intensa e primorosa pesquisa histórica, com base em documentos e entrevistas, descrevendo com detalhes as operações realizadas pelos grupos norte-americanos na referida crise. As inúmeras ações norte-americanas, que contaram com maciça colaboração das oposições locais (sobretudo as denominadas "ilhas de sanidade"2), foram, de acordo com Moniz Bandeira, direcionadas para todas as classes sociais e coordenadas pela CIA. Esta última "não somente aliciou empresários, vereadores, deputados estaduais e federais, senadores, governadores de estado, mas também jornalistas, donas de casa, estudantes, dirigentes sindicais, padres e camponeses, enfim, elementos de todas as classes e categorias da sociedade civil brasileira" (idem, p. 84).

\footnotetext{
1 Nesse programa destacavam-se as propostas de reforma agránia e da lei que regulava as remessas de lucros para o exterior, que interferia diretamente nos interesses das empresas multinacionais (ver MONIZ BANDEIRA, 2001, p. 163-171).

2 Essa expressão foi usada pelo govemo norte-americano na época para fazer menção aos estados que faziamoposição ao govemo Goulart. Destaque para São Paulo, Minas Gerais e Guanabara (ver TOLEDO, 1982 p. 107-108).
} 
O autor refere-se aos posicionamentos de João Goulart enfatizando o caráter de sua liderança trabalhista, a qual, sustentada por um eleitorado de base operária, contribuiu para reforçar as pretensões nacionalistas no período, em detrimento dos interesses conservadores e internacionais. Nesse panorama, conforme Moniz Bandeira, "as atitudes de Goulart, antes sempre inclinadas ao entendimento, indicavam que ele aceitara o desafio e demonstravam, claramente, [que o Presidente] não mais nutria qualquer ilusão de compromisso, muito menos com os EUA" (idem, p.149).

Essas duas temáticas fundamentam e desenvolvem a tese principal de Moniz Bandeira. Além do mais, o livro, pela riqueza de detalhes históricos, fornece subsídios para o leitor pensar inúmeras questões específicas, como por exemplo a atuação dos militares ou as posições dos parlamentares da época, fossem esses "legalistas" ou "golpistas".

Teoricamente, as interpretações da crise de 1964 podem ser identificadas e resumidas em duas grandes correntes explicativas: a "estrutural” e a "intencional” (FIGUEIREDO, 1993, p. 22-29). As explicações estruturais são divididas em dois tipos. O primeiro enfatiza os fatores econômicos, basicamente aqueles ligados à necessidade de manutenção de modelo de acumulação capitalista concentrador de renda. Destaco, nesse caso, o trabalho de Guillermo O'Donnell (1987). O segundo tipo prioriza os fatores políticos, isto é, as disputas pelos recursos de poder em função da estrutura política vigente. Wanderley Guilherme dos Santos (1986) aparece como um dos principais expoentes dessa vertente.

Esses dois tipos de explicação, a política e a econômica, sugerem a idéia de "inevitabilidade" do golpe de Estado, uma vez que a "margem deixada para a escolha [dos cursos de ação pelos atores] é tão pequena que a própria escolha torna-se irrelevante, e a ação, consequientemente, vã” (FIGUEIREDO, 1993, p. 23).

O modelo de análise intencional também pode ser dividido em duas vertentes explicativas. A primeira enfoca o processo conspiratório regido pelos grupos conservadores (sejam esses nacionais ou internacionais) como determinante do colapso do populismo brasileiro. Destaque-se aqui a prestigiosa interpretação de René Dreifuss, um dos estudiosos mais importantes desse estilo de explicação, que sugere, lançando mão do conceito gramsciano de "elite orgânica", o golpe de 1964 como conseqüência da mobilização envolvendo empresários ligados ao capital estrangeiro (DREIFUSS, 1981, p. 481-488).

A segunda variação da interpretação intencionalista toma como referência as posturas políticas de João Goulart durante a crise. O Presidente, alternando ações ora de conciliação, ora de ruptura, acabou por minar as bases de sustentação política do populismo. Nessa linha, menciono o trabalho de Caio Navarro de Toledo, no qual se lê que "o governo Goulart nem conseguia o pleno respaldo das classes populares e trabalhadoras, nem se legitimava face ao conjunto das classes dominantes” (TOLEDO, 1982, p. 119).

A compreensão intencional dos fatos relacionados ao golpe de 1964 prende-se, em geral, a um estilo impressionista, com destaque para a crônica dos eventos e a atuação pontual de cada personagem na cena política. Todos os acontecimentos passam a ser conseqüência da notável (ou desastrosa, segundo o caso) estratégia desses atores individuais. Inexistem considerações, nesse modelo explicativo, sobre as relações globais tanto dos grupos conspiradores quanto de Goulart com os vários atores políticos do referido período de crise.

A partir dessa brevíssima revisão de literatura, sugiro que as conclusões de Moniz Bandeira enquadram-se duplamente na linha explicativa intencional da literatura especializada sobre o tema. A "intencionalidade" que está na base da argumentação do autor expressa-se em sua hipótese de conspiração norte-americana, intimamente ligada à radicalização do programa de "Reformas de Base”. Sua sugestão está muito próxima da conclusão de Dreifuss. Mas ao considerar a etapa de radicalização das reformas como elemento importante no processo, Moniz Bandeira lança mão de argumentos inerentes à segunda variação explicativa intencional, na qual Goulart é tomado como referência.

Se, por um lado, a explicação que Moniz Bandeira oferece deixa a desejar, por outro lado seu trabalho pioneiro (note-se que a primeira edição do livro foi em 1977) possui como grande contribuição uma excelente pesquisa histórica, que, apoiada numa metodologia aperfeiçoada em consultas a fontes primárias e secundárias, juntamente com um arsenal de entrevistas muito proveitoso ${ }^{3}$, propicia ao leitor uma boa reprodução dos

\footnotetext{
3 Faço essa observação considerando que o recurso a entrevistas é muito importante em pesquisas relacionadas à história política, pois, levando em conta a dificuldade de acesso às fontes primárias, a memória política das personalidades da época
} 
episódios na época.

Mas um ponto merece mais atenção que os demais: o redimensionamento do papel de Goulart no período 1961-1964. Essa temática mostra-se muito interessante para discutir um conceito teórico clássico da Sociologia Política brasileira: o populismo ${ }^{4}$.

De acordo com a sugestão teórica de Francisco Weffort, o "populismo" é um fenômeno político de massas, típico das "regiões atingidas pela intensificação do processo de urbanização", pautado por uma relação específica entre os indivíduos e o poder político; esse poder é exercido através de um líder carismático tutelador, "em contato direto com os indivíduos reunidos na massa" (WEFFORT, 1978, p. 28).

Weffort ressalta que essa dominação carismática deve ser compreendida "como uma expressão política de interesses determinados de classe" (idem, p. 26). Nesse caso, destaca a consciência "pequeno-burguesa" $\mathrm{da}$ massa, supondo que esta aparece como classe somente através do líder carismático, o seu representante político. Diante dessa dinâmica, os protestos populares atingem o núcleo decisório do aparelho estatal, assumindo, devido aos apelos ideológicos e demagógicos da liderança, um caráter de participação política passiva.

Conforme a interpretação de Moniz Bandeira, Goulart não "atuava como demagogo, que entorpecia as massas e as desorganizava, para resguardar o domínio do grande capital, a exemplo do que Jânio Quadros e Adhemar de Barros faziam", mas como um reformista orientado por uma massa organizada "nos sindicatos e em um partido político, o PTB” (MONIZ BANDEIRA, 2001, p. 52-53).

O leitor poderá identificar, a partir da leitura atenta, que Moniz Bandeira discorda de que o projeto político do governo Goulart seja considerado "populista". Quais são seus argumentos? O que autor sustenta como elemento diferenciador se comparado com a definição de Weffort? Sem sombra de dúvida, o governo de Jango se pautaria por um nacional-reformismo planejado a partir de instituições organizadas (no caso, os sindicatos e o PTB), que, conforme Moniz Bandeira, determinaram a participação popular direta, bloqueando a tutela por parte do poder estatal. Essa concepção torna-se evidente quando o autor faz menção ao Partido Trabalhista Brasileiro (PTB). De acordo com Moniz Bandeira, o PTB foi, "bem ou mal, um partido de composição operária, cuja práxis mais se assemelhava à da social-democracia européia depois da guerra de 1914-1918, nas condições históricas do Brasil, do que à práxis do populismo" (idem, p. 53).

Weffort sugere que o "nacional-reformismo" foi, no período pré-64, uma expressão global muito próxima do "populismo", baseada na noção abstrata de "povo". Mas esta era oriunda do próprio Estado, sem liderança carismática e organização partidária eficientes. "A ideologia nasce, pois, dentro do Estado ou em associação com ele, embora pretenda traduzir os interesses gerais de todo o povo" (WEFFORT, 1978, p. 40). Conclui que "essa ideologia foi pouco mais que uma forma pequeno-burguesa de consagração do Estado" (idem, p. 42), e este, "tal como estava estruturado, já não era capaz de nenhuma ação" (idem, p. 43) autônoma.

Conclusão: as idéias de nacional-reformismo em Moniz Bandeira e Weffort são completamente diversas. Enquanto para Weffort a orientação nacionalista adota "as mesmas idéias confusas que os populistas propunham às massas na demagogia dos grandes comícios" (idem, p. 37), expressas na noção de "povo" e atua, de maneira ineficiente, supervalorizando a esfera estatal, Moniz Bandeira compreende o reformismo nacionalista como uma expressão de atuação direta das massas organizadas no processo político decisório, pois os sindicatos, e principalmente o PTB, conforme o autor, configuram-se como legítimos instrumentos de vocalização da aspiração popular.

ilustra o referido cenário político e, se bemaproveitada, possibilita a abertura de caminhos a outras fontes que, até então, poderiamser desconhecidas do pesquisador.

4 Porminhaopção, tomarei como referência o conceito de "populismo" daescola paulista de Sociologia Política, particularmente a definição de Francisco Weffort. Entendo que essa concepção é a mais adequada para uma discussão a partir das considerações de Moniz Bandeira.

5 Nessa definição, Weffort ressalta o papel da pequena burguesia, que, comsua incapacidade de organização política, tende a assumir, emsuas manifestações, uma condição de classe "no momento emaparece como massa devotada a um chefe". Éa consciência pequeno-burguesa do populismo, expressa, principalmente, no "ademarismo e no janismo" (ver WEFFORT, 1978, p. 29-30). 
Esse otimismo tem uma sólida razão política. O leitor deve levar em conta que Moniz Bandeira foi um militante trabalhista no período, pois era "assessor do deputado Sérgio Magalhães, do PTB, presidente da Frente Parlamentar Nacionalista e vice-presidente da Câmara Federal” (MONIZ BANDEIRA, 2001, p. 11). Esse fato, muito provavelmente, teve uma significativa influência nos posicionamentos do autor.

Considerações partidárias à parte, O governo João Goulart: as lutas sociais no Brasil (1961-1964) apresentase ao leitor como uma obra muito interessante devido ao denso levantamento histórico realizado por Luiz Alberto Moniz Bandeira. É, sem dúvida, ainda uma referência indispensável para os estudiosos do tema.

Recebida para publicação em 17 de novembro de 2001. Resenha aprovada em 23 de novembro de 2001.

Marcus Roberto de Oliveira (mr_olivei@yahoo.com.br) é graduado em Ciências Sociais pela Universidade Federal do Paraná (UFPR) e pesquisador do Núcleo de Pesquisa em Sociologia Política Brasileira da UFPR.

\section{REFERÊNCIAS BIBLIOGRÁFICAS}

DREIFUSS, R. A. 1981. 1964: a conquista do estado. Petrópolis : Vozes.

FIGUEIREDO, A. C. 1993. Democracia ou reformas? Alternativas democráticas à crise política (1961-1964). São Paulo : Paz e Terra.

O’DONNELL, G. 1987. BA: Reflexões sobre os Estados burocráticos autoritários. São Paulo : Vértice.

SANTOS, W. G. 1986. 64: anatomia da crise. São Paulo : Vértice.

TOLEDO, C. N. 1982. O governo Goulart e o golpe de 64. São Paulo : Brasiliense.

WEFFORT, F. 1978. O populismo na politica brasileira. Rio de Janeiro : Paz e Terra. 